\title{
Potential adverse health effects of dietary lipid oxidation products
}

\author{
Yuanyuan $\mathrm{Hu}^{\mathrm{a}}$, Guanhua Zhao ${ }^{\mathrm{a}}$, Min Zhang ${ }^{\mathrm{a}}$, Dayong Zhou ${ }^{\mathrm{a}, \mathrm{b}, \mathrm{c}^{*}}$ and Beiwei Zhu $\mathrm{Z}^{\mathrm{a}, \mathrm{b}, \mathrm{c}^{*}}$
}

\begin{abstract}
aSchool of Food Science and Technology, Dalian Polytechnic University, Dalian 116034, PR China
bNational Engineering Research Center of Seafood, Dalian 116034, PR China

${ }^{\mathrm{c} C o l l a b o r a t i v e ~ I n n o v a t i o n ~ C e n t e r ~ o f ~ S e a f o o d ~ D e e p ~ P r o c e s s i n g, ~ D a l i a n ~ P o l y t e c h n i c ~ U n i v e r s i t y, ~ D a l i a ~ 116034, ~ P R ~ C h i n a ~}$

*Corresponding author: Dayong Zhou and Beiwei Zhu, School of Food Science and Technology, Dalian Polytechnic University, Dalian 116034, PR China. Tel: +86-0411 86323453 (BZ), +86-041186313453 (DZ); E-mail: zdyzf1@163.com (DZ), zhubeiwei@163.com (BZ)

DOI: $10.31665 /$ JFB.2021.15282
\end{abstract}

Received: July 17, 2021; Revised received \& accepted: August 11, 2021

Abbreviations: A $\beta$, amyloid $\beta$-protein; ACE, angiotensin converting enzyme; ACh, acetylcholine; AD, Alzheimer's disease; ADAM, Adisintegrin and metalloprotease; ALDH2, aldehyde dehydrogenase-2; ALS, amyotrophic lateral sclerosis; ApoE-/-, apolipoprotein E-deficient; APP, amyloid precursor protein; AST, aspartate aminotransferase; ATP, adenosine-triphosphate; BACE-1, beta-secretase 1; BCL-2, B-cell lymphoma 2; BDNF, brain-derived neurotrophic factor; BK, large-conductance calcium-dependent potassium; CAT, catalase; CCK, cholecystokinin; CoA, acyl coenzyme A; COPs, cholesterol oxidation products; CYP, cytochrome P450; dGuo, 2'-deoxyguanosine; DNA, deoxyribonucleic acid; FAS, fatty acid synthase; G6PDH, glucose-6-phosphate dehydrogenase; GPR183, G protein-coupled receptor 183; GPx, glutathione peroxidases; GSH, glutathione; HD, Hungtington's disease; HHE, 4-hydroxy-2-hexenal; HNE, 4-hydroxy-2-nonenal; KATP, adenosine triphosphate-sensitive potassium; 7-KC, 7-ketocholesterol; LDL, low-density lipoprotein; LOPs, lipid oxidation products; MAPK, mitogen-activated protein kinase; MDA, malondialdehyde; NF- $\kappa \mathrm{B}$, nuclear factor kappa light chain enhancer of activated B cells; NO, nitric oxide; 24-OH, 24-hydroxycholesterol; 27-OH, 27-hydroxycholesterol; PD, Parkinson; PE, phenylephrine; PKC, protein kinase C; PPAR $\alpha$, peroxisome proliferator-activated receptor $\alpha$; PUFAs, polyunsaturated fatty acids; ROS, reactive oxygen species; SNP, sodium nitroprusside; SREBP, sterol regulatory element binding protein; t-2-DCA, trans-2-decenal; tt-DDE: trans, trans-2,4-decadienal; tt-2,4-NDE, trans-trans-2,4-nonadienal; TrkA, tropomyosin receptor kinases A; TrkB, tyrosine Kinase receptor B; t-2-UDA, trans-2-undecenal; VLDL, very low-density lipoproteins; ZO-1, occlusion-1

Citation: Hu, Y., Zhao, G., Zhang, M., Zhou, D., and Zhu, B. (2021). Potential adverse health effects of dietary lipid oxidation products. J. Food Bioact. 15: 51-62.

\begin{abstract}
Lipid oxidation products (LOPs) are widely present in many lipid- containing foods. They usually enter the gastrointestinal tract from dietary sources and/or are produced in vivo. Part of LOPs were absorbed into the blood and transported into tissues. A growing bulk of evidence suggests that LOPs, mainly reactive aldehydes and oxysterols, are potentially involved in the pathogenesis of many chronic diseases, such as atherosclerosis, Alzheimer's disease, and inflammatory bowel disease. This review summarizes the current knowledge of the adverse effects, cytotoxicity, and the main mechanisms of LOPs involvement in humans and animals.
\end{abstract}

Keywords: Lipid oxidation products; Aldehyde; Cholesterol oxidation products; Adverse health effects; Toxicity.

\section{Introduction}

Lipids are the main nutrient components of food and important components of cells in biological systems. However, they are prone to oxidation through various pathways. Lipid oxidation is not only a major reason for the deterioration of food quality, but also has negative impacts on the integrity of the biological system (Shahidi and Zhong, 2010). The lipid oxidation process involves a series of complex reactions, producing a large number of lipid oxidation products (LOPs), including lipid hydroperoxides, aldehydes, ketones, alcohols, alcohols, and epoxy compounds, among others (Rodriguez-Amaya and Shahidi, 2021). These oxidative changes in lipids or lipid containing foods result in the formation of peculiar smell, the loss of nutrients and bioactives, making foods unsuitable for consumption, and even formation of toxic compounds, which potentially risk to human health.

With the diversification of people's diet, an increasingly large 


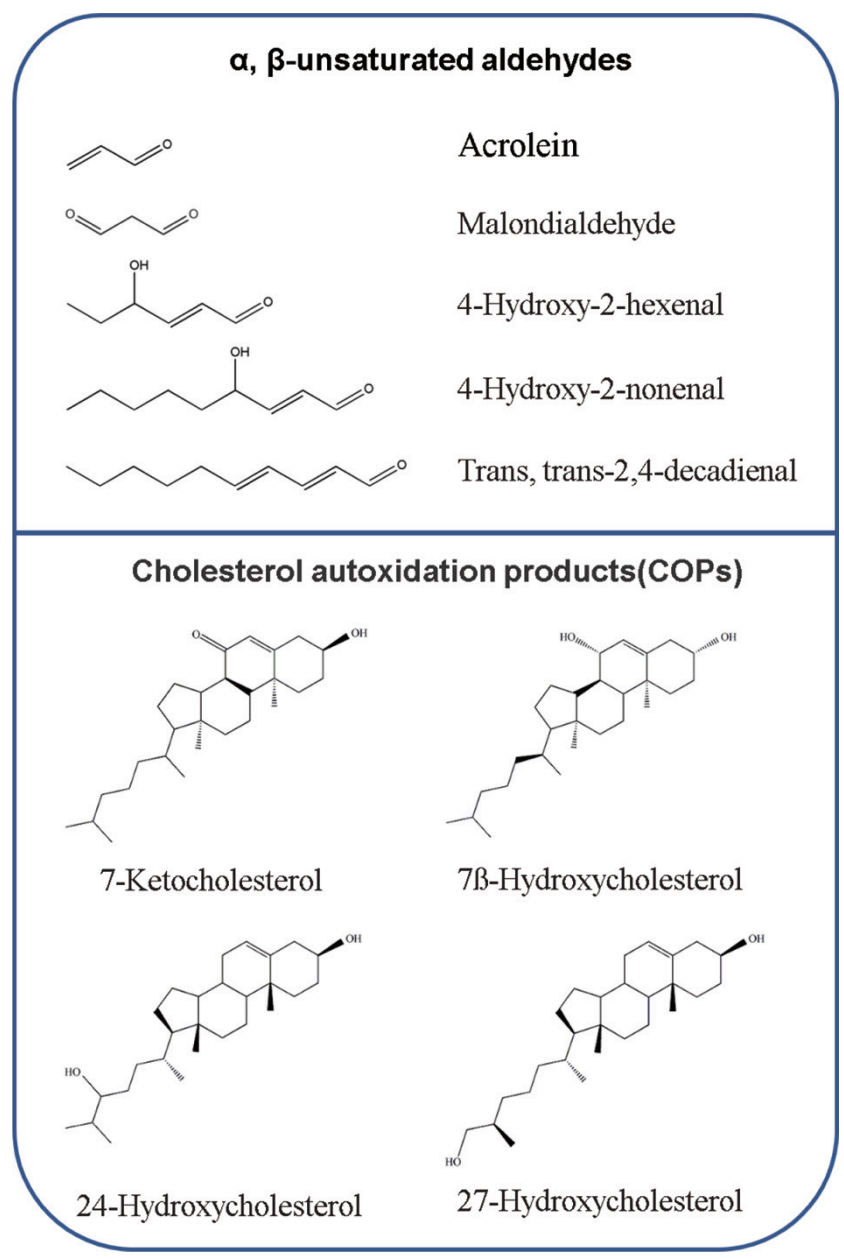

Figure 1. Examples of chemical structures of the lipid oxidation products (LOPs).

proportion of the human population frequently ingest oxidized/peroxidized lipids. Oxidized/peroxidized lipids may contain a class of toxic compounds including hydroxyl fatty acids, cyclic monomers, dimers, and polymers and polycyclic aromatic hydrocarbons (Rodriguez-Amaya and Shahidi, 2021). Besides, dietary oxidized/ peroxidized lipids exist in gastrointestinal tract constantly, and decompose into a variety of oxygenated and aliphatic fatty acid scission as well as secondary or tertiary lipid oxidation products in the gastric lumen (Vieira, Zhang, and Decker, 2017). Some of them are easily absorbed into the lymph or directly into the blood stream after ingestion (Kanner, 2007). In the past decades, the deleterious effects of regular ingestion of these LOPs on human health have attracted a large amount of high-impacting research interest and focus.

Although a myriad of compounds may be formed during lipid oxidation, the mainly focused research areas are the oxidation products of polyunsaturated fatty acids (PUFAs) and cholesterol oxidation products (COPs) (Figure 1). For PUFAs, hydroperoxides from PUFA oxidation undergoes $\beta$-cleavage and produces various species of aldehydes. Among these aldehydic end-products, reactive $\alpha, \beta$-unsaturated aldehydes, such as 4-hydroxy-2-nonenal (HNE), 4-hydroxy-2-hexenal (HHE), acrolein, malondialdehyde (MDA), and trans, trans-2,4-decadienal (tt-DDE), are the most important secondary oxidation products in terms of both quantity and toxici- ty (Guillén and Goicoechea, 2008; Rodriguez-Amaya and Shahidi, 2021). Accumulated evidence shows that they are regarded as the second messengers of free radicals and possess potent electrophilic properties that could interfere with many pathophysiological processes, and exert toxic effects in both human and animal studies (Gęgotek and Skrzydlewska, 2019). For cholesterol, oxidation of cholesterol leads to the formation of a large number of oxidized products, generally known as oxysterols. They are important mediators of cholesterol-induced effects with detrimental properties. They can enter intracellular membranes and affect the structure and function of membrane-associated proteins (Maldonado-Pereira et al., 2018; Testa et al., 2018). Solid evidence indicates that these aldehydes and COPs are implicated in or could aggravate a series of adverse effects on human health, such as cardiovascular diseases, neurodegenerative diseases, mutagenic and carcinogenic properties, gastrointestinal disease, and hepatotoxicity (Table 1). However, very few reviews of this topic have been published.

Taking into account the increasing tendency to enrich foods with LOPs and the increasing incidence of the related diseases, this review summarizes the current knowledge about the studies of LOPs and the related diseases. This evidence might help to enhance people's awareness of the health effects of dietary oxidized lipids and provide potential therapeutic directions for reducing the LOPs related diseases.

\section{Cardiovascular diseases}

\subsection{Atherosclerosis}

Oxidized lipid and LOPs in foods are absorbed by the intestine, appear in the blood circulation, and can have deleterious cardiovascular effects in humans (Cohn, 2002). Atherosclerosis is a progressive disease characterized by the accumulation of lipid and fibrous components in the large arteries (Zaguri et al., 2007). Numerous studies from both animals and humans indicate that dietary oxidized lipids, aldehydic LOPs, and COPs have some atherosclerotic effects. Accumulated evidence shows that people who consume LOPs have significant higher oxidized lipids level in chylomicrons and very low density lipoproteins (VLDL), which is positively associated with the occurrence of clinical evidence of atherosclerosis in humans (Ahotupa, 2017; Hajri, 2018; Viktorinova et al., 2016). Another human study conducted by Menéndez-Carreño et al. (2011) analyzed the relationship between total COPs and different cardiovascular diseases risk factors in the serum of 88 recruited subjects. The results showed that the serum COPs level of patients with atherosclerosis was significantly higher than those of subjects who did not show atherosclerosis. More recent investigation reported that serum 7ß-hydroxycholesterol concentration was the strongest predictor of a rapid progression of carotid atherosclerosis in humans (Maldonado-Pereira, et al. 2018). All these evidences have emphasized the close relationship between arteriosclerosis and LOPs.

In animal experiments, the COPs have been found to have profound biological effects following the intake of meals rich in oxidized cholesterol, such as increased aortic injury, impaired vascular endothelium, and which also support the role of LOPs in atherosclerosis. Staprans et al. $(2000 ; 2005)$ found that dietary oxidized cholesterol for respective 7 and 4 months significantly increased aortic lesions in apolipoprotein E (ApoE) and low density lipoproteins (LDL) receptor-deficient mice. Meynier et al. (2002) reported that administration of oxysterols in high cholesterol diets for 3 months induced vascular wall thickening, endothelial damage and smooth muscle cell proliferation and migration in Golden 


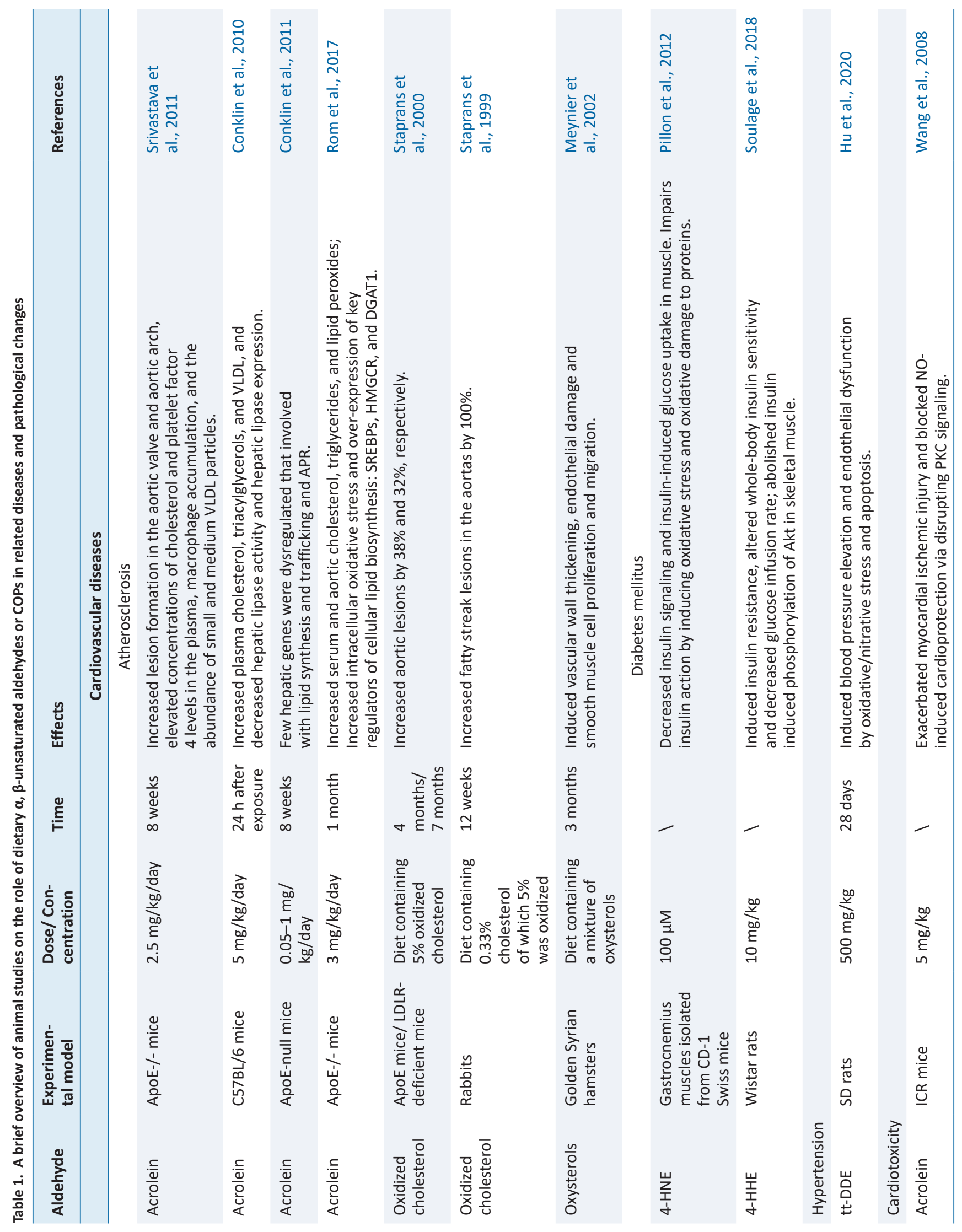




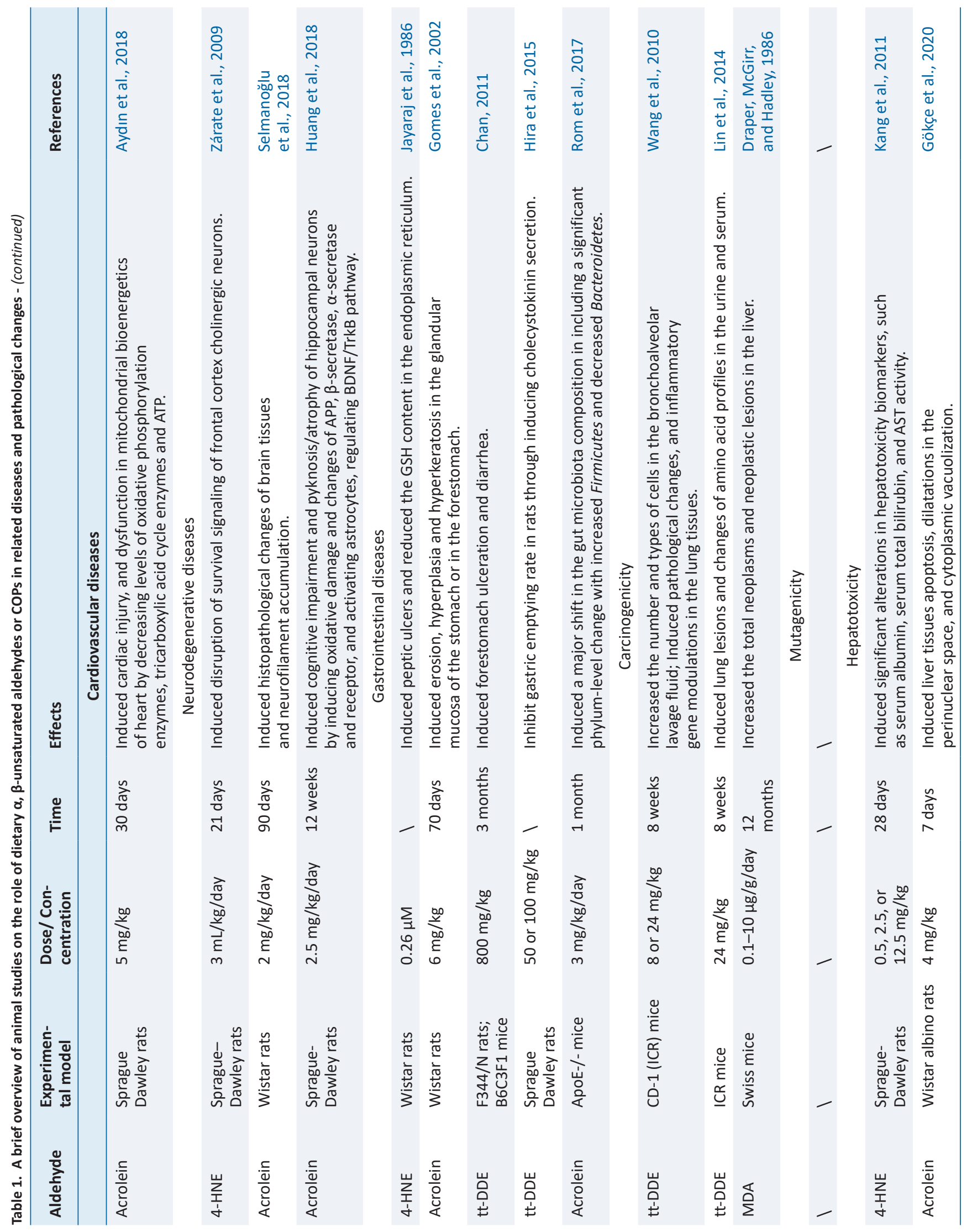




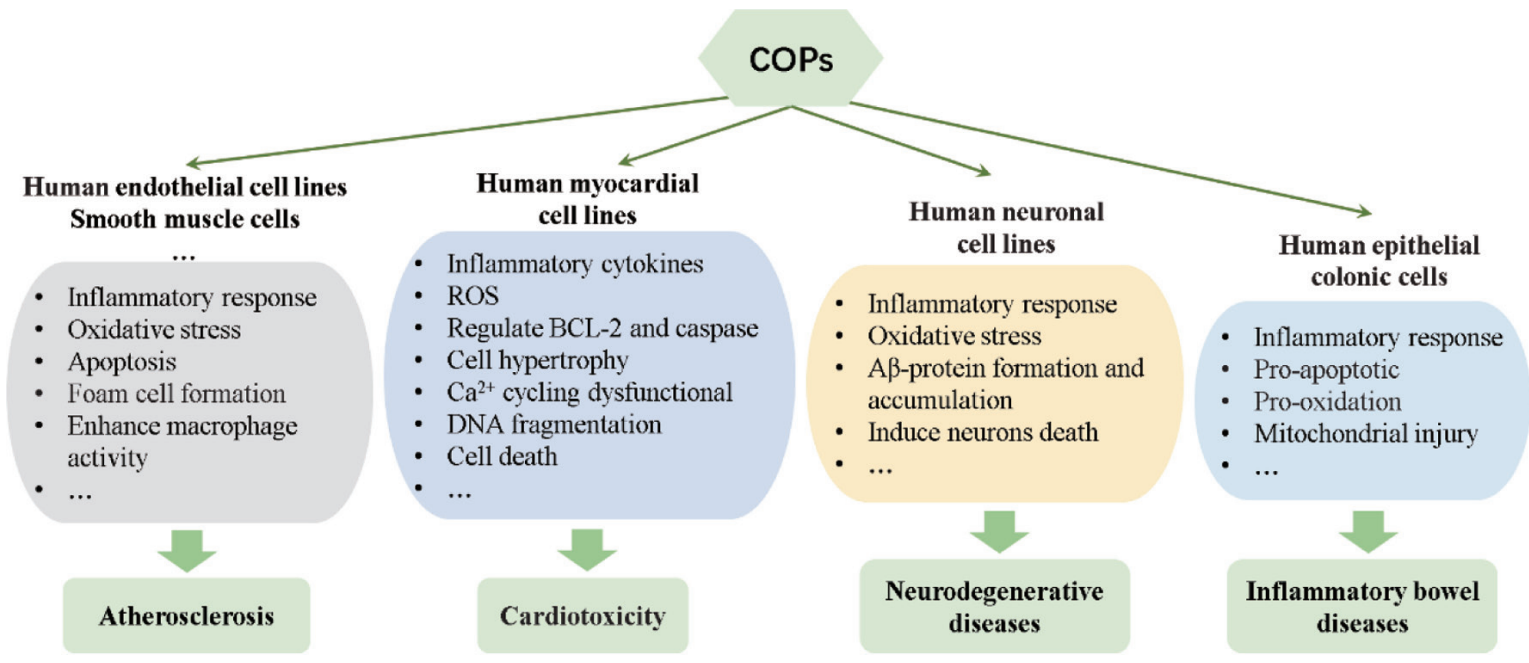

Figure 2. The effects of COPs on different cell lines that involved in various diseases.

Syrian hamsters. Besides, Gargiulo et al. (2017) reviewed that oxysterols contribute to atherosclerosis by inducing apoptosis, oxidative stress, chronic inflammation, foam cell formation, mitochondrial damage, loss of nitric oxide (NO) bioavailability, as well as enhancing macrophage activity in vitro (Figure 2).

In addition to oxysterols, several previous publications reviewed that aldehydes are involved in the genesis and development of atherosclerosis by inducing various key steps, including damage endothelial function, modification of LDL, promotion foam cell formation, stimulation the adhesion of monocytes and lymphocytes, proinflammatory, redox imbalance, deoxyribonucleic acid (DNA) damage, formation of the monocyte chemoattractant protein-1, and stimulation smooth muscle cells proliferation and migration (Leonarduzzi et al., 2010; Zirak et al., 2019). In this review, the collected evidence suggests that aldehydes, especially acrolein, contribute to the development of atherosclerosis by inducing vascular injury, systemic dyslipidemia, and gut microbiota in vivo. According to the results reported by Srivastava et al. (2011), dietary exposure to acrolein $(2.5 \mathrm{mg} / \mathrm{kg} /$ day $)$ by gavage for 8 weeks aggravated atherosclerosis in apolipoprotein E-deficient (ApoE-/) mice, as evidenced by increased lesion formation in the aortic valve and aortic arch, elevated concentrations of cholesterol and platelet factor 4 levels in the plasma, macrophage accumulation, and the abundance of small and medium VLDL particles. Conklin and co-workers reported that oral acrolein feeding resulted in increased plasma cholesterol, triacylglycerols, and VLDL, and decreased hepatic lipase activity and hepatic lipase expression in mice (Conklin et al., 2010; Conklin et al., 2011). Rom et al. (2017) found that feeding ApoE-/- mice with acrolein ( $3 \mathrm{mg} / \mathrm{kg} /$ day) for 1 month resulted in a significant dyslipidemia as well as elevations of the prevalence of Ruminococcaceae and Lachnospiraceae, and this altered the gut microbiota composition is positively correlated with enhanced atherosclerosis.

Taken together, these findings indicate that LOPs in the diet are directly related to the level of oxidized lipids in the circulation, which can trigger the occurrence of atherosclerosis involved in a variety of complex ways.

\subsection{Diabetes mellitus}

Based on the preceding evidence, the process of lipid oxidation and the resulting LOPs are implicated in the development of diabetes and its complications. Indeed, a study based on the results of human trials in diabetic patients showed that the level of oxidized lipids in serum chylomicrons increased after people with poor blood glycemic control ingested dietary oxidized fatty acids (Staprans et al., 1999). Besides, oral consumption of a diet contains high oxidized frying oil are demonstrated to induce impairment of glucose tolerance and impairment of insulin secretion in rodents ( $\mathrm{Li}$ et al., 2017; Liao, Shaw, and Chao, 2008). Notably, HNE is considered as a crucial molecule for triggering and sustaining a wide range of biochemical events underlying the development of this processes (Jaganjac et al., 2013). It has been reported that HNE could directly bind to insulin and consequently impair its ability to stimulate glucose uptake in mice (Pillon et al., 2011; Pillon et al., 2012). Following these findings, another by-product of n-3 PUFAs peroxidation, HHE, which has similarities in structure with HNE, was reported to play a causal role in the pathophysiology of type 2 diabetes. The researchers found that circulating levels of HHE in type 2 diabetic humans and diabetic rat models were twice that of non-diabetic counterparts, and it was positively correlated with blood glucose levels. Acute intravenous injection of HHE (10 mg/ $\mathrm{kg}$ ) significantly changed the whole-body insulin sensitivity and reduced the glucose infusion rate in rats (Soulage et al., 2018). Moreover, both HNE and HHE were found to impair insulin action, insulin signaling, and insulin-induced glucose uptake in muscle cells and adipose cells (Cohen et al., 2013; Pillon et al., 2012; Soulage et al., 2018).

For COPs, some evidences show high concentrations of plasma COPs in patients or animals with diabetes mellitus compared with healthy controls (Endo et al., 2008; Ferderbar et al., 2007; Yoshioka et al., 2005). However, the question whether dietary COPs can directly lead to the development of diabetes mellitus needs more research to prove.

\subsection{Hypertension}

As we all know, hypertension is one of the most common chronic diseases, and also an important risk factor for cardiovascular disease. Vascular endothelial dysfunction contributes to the occurrence and development of vascular injury, and it is also an effective independent predictor of hypertension (Endemann and 
Schiffrin, 2004). Evidences from humans and animals indicate that intake of LOPs may be a potential risk factor for the development of hypertension. A human study conducted by Soriguer et al. (2003) reported that LOPs produced from cooking oil were strongly and positively associated with high blood pressure. In animal experiments, administration of oxidized lipids was reported to induce hypertension by impairing endothelium-dependent and endothelium-independent vasorelaxation, reducing NO bioavailability, increasing thromboxane and angiotensin converting enzyme (ACE), altering the histological structures of blood vessels, and reducing adenosine triphosphate-sensitive potassium (KATP) and large-conductance calcium-dependent potassium channels (BK channels). For example, intake of oxidized oils for 6 months was reported to induce blood pressure elevation, attenuate relaxations in response to acetylcholine $(\mathrm{ACh})$ and sodium nitroprusside (SNP) as well as increase vasoconstriction to phenylephrine (PE) (Leong et al., 2009; Nurul-Iman et al., 2013). Other studies point that ingestion of thermally oxidized oil for 16 weeks induced blood pressure elevation, disrupted elastic lamellae of tunica media and the structures of heart and blood vessels, and simultaneously with increased thromboxane and ACE in rats (Nkanu, Owu, and Osim, 2018; Siti et al., 2017; Siti et al., 2018).

Accumulated evidence reveals that oxidative stress is one of the important reasons leading to the generation and/or maintenance of hypertension, which can directly change the function of vascular endothelial or cause changes in vascular tension (Hu et al., 2020). As an inducer of reactive oxygen species (ROS), reactive aldehydes were regarded as an important mediator of oxidized lipids in inducing blood pressure elevation. Indeed, Conklin et al. (2006) concluded that acrolein generation in the blood vessel wall increased human susceptibility to vasospasm, an event that is enhanced in hypertension. Recently, it was demonstrated that oral administration of tt-DDE $(500 \mathrm{mg} / \mathrm{kg})$ for 28 day induced blood pressure elevation in rats, and this effect was closely associated with tt-DDE induced endothelial dysfunction, oxidative/nitrative stress and apoptosis in both vascular endothelial tissue and endothelial cells (Hu et al., 2020). Besides, other evidences indicate that excess reactive aldehydes contribute to progressive and deleterious changes in hypertensive by increasing cytosolic-free calcium levels, altering renal vascular function, and inducing endothelial cell toxicity (Hu et al., 2020; Lee and Park, 2013).

\subsection{Cardiotoxicity}

In addition to their role in the process of atherosclerosis, diabetes, and hypertension some evidences indicate that LOPs are detrimental to heart and cardiac function, and instigate multiple cellular disturbances in cardiomyocytes (Hajri, 2018). Indeed, consumption of oxidized rapeseed oil for 112 days induced transient myocardial lipidosis characterized by accumulation of fat droplets in myocardial fibers of rats (Charlton et al., 1975). Rouaki et al. (2013) reported that dietary oxidized sunflower oil induced extensive necrosis of heart tissue, increased body weight and LPO levels, and decreased catalase (CAT) and glutathione peroxidases (GPx) activities in rats. Again, other studies found that dietary heated palm oil diet for 16 weeks significantly increased the myofiber width and area, and induced necrosis in cardiac tissue of rats (Kamisah et al., 2016; Leong et al., 2008).

Specially, reactive aldehydes including acrolein and HNE are consistently demonstrated to be the important mediators that contribute to cardiotoxicity. The immunohistochemical examination of myocardial biopsy in patients with cardiomyopathy and/or heart failure showed that HNE protein adduct increased in the heart and was positively correlated with decreased heart function (Nakamura et al., 2005). Another study reported that HNE can form adducts with cardiac aldehyde dehydrogenase 2 (ALDH2) protein in metabolic syndrome and/or type 2 diabetic mice, accompanied by obvious cardiac hypertrophy, cardiac damage, myocardial mitochondrial dysfunction, and heart weight increase (Mali et al., 2016). For acrolein, Wang et al. (2008) found that acrolein $(5 \mathrm{mg} / \mathrm{kg})$ feeding by gavage could exacerbate myocardial ischemic injury and blocks NO-induced cardioprotection via mechanisms that disrupt protein kinase C (PKC) signaling in mice. Aydın et al. (2018) reported that oral administration of acrolein $(5 \mathrm{mg} / \mathrm{kg})$ in rats for 30 days induced cardiac injury, with oxidative stress and dysfunction in mitochondrial bioenergetics of heart. On the other hand, reactive aldehydes can induce a wide array of toxic consequences in the cardiomyocytes, including destruction of membrane and cytosolic enzyme activities and actin cytoskeleton, inducing mitochondrial damage, depletion of adenosine-triphosphate (ATP) content, membrane swelling and dissolution, alteration of current through $\mathrm{K}^{+}$ channels, imbalance of cellular calcium homeostasis, and inducing oxidative stress, inflammation, and apoptosis (Chapple, Cheng, and Mann, 2013; Gianazza et al., 2019).

For oxysterol, there are significant positive correlations between oxysterol levels and the number of risk factors for coronary heart disease (Samadi et al., 2019). Besides, in a study of Sozen et al. (2018), the data indicated that a high-cholesterol diet caused abnormal heart function by regulating proteins related to lipid metabolism in rabbits. In vitro, oxysterols also exert strong toxic effects on the cardiomyocytes, including increasing inflammatory cytokine, downregulation of B-cell lymphoma 2 (BCL-2) expression, activation of caspases, production of ROS, opening of mitochondrial permeability transition pore, inducing cell hypertrophy, $\mathrm{Ca}^{2+}$ cycling dysfunctional, DNA fragmentation, and cell death (Cilla et al., 2017; Lee, Nam, and Lee, 2015) (Figure 2). However, more human and animal experiments need to be provided to prove the potential role of COPs intake and cardiotoxicity.

\section{Neurodegenerative diseases}

Documented evidences have demonstrated that free radical-mediated oxidative damage is one of the important mechanisms of the pathogenesis of neurodegenerative diseases, including Alzheimer's disease (AD), Parkinson (PD), Hungtington's disease (HD), and Amyotrophic lateral sclerosis (ALS). Since HNE acts both as a signaling molecule and as cytotoxic product, its effect on neurodegenerative diseases has been extensively investigated. Perluigi et al. (2012) pointed that there were elevated levels of HNE and its proteins adducts in relevant brain tissues and body fluids of AD, PD, HD subjects and/or animal models with neurodegenerative diseases. The formation of protein adducts results in altered energy metabolism and protein homeostasis, mitochondrial dysfunction, as well as reduced antioxidant levels, which provides further support for the physical impairment, cognitive decline, progressive memory loss, and oxidative stress associated with the neurodegenerative disorders (Barrera et al., 2015). For example, Sardar Sinhah et al. (2018) reported that HNE was implicated in the pathogenesis of different PD by modifying $\alpha$-synuclein, an important protein that linked to synaptic plasticity, neurotransmitter release and the maintenance of the synaptic pool. On the other hand, intake of HNE can induce direct adverse effects on neurons and neural cells. Zárate et al. (2009) reported that administration of oxidized sunflower oil containing HNE ( $3 \mathrm{~mL} / \mathrm{kg} /$ day) for 21 days induced disruption of survival signaling of frontal cortex choliner- 
gic neurons, as evidenced by the reduction of the number of neural cells with positive immunostained tropomyosin receptor kinases A (TrkA) receptor in the frontal cortex of rats.

In addition to HNE, Selmanoğlu et al. (2018) reported that oral exposure to acrolein $(2 \mathrm{mg} / \mathrm{kg} /$ day $)$ for 90 days induced histopathological changes of brain tissues and neurofilament accumulation in rats. Huang et al. (2018) found that acrolein $(2.5 \mathrm{mg} / \mathrm{kg} /$ day) treatment by gavage for 12 weeks induced cognitive impairment and pyknosis/atrophy of hippocampal neurons by inducing oxidative damage, activating astrocytes, regulating brain-derived neurotrophic factor $(\mathrm{BDNF}) /$ tyrosine Kinase receptor B (TrkB) pathway, $\beta$-secretase 1 (BACE-1) and A-disintegrin and metalloprotease (ADAM) in hippocampus and cortex, as well as key enzymes involved in amyloid precursor protein (APP) metabolism in rats.

Oxysterols are believed to be the link between altered brain cholesterol metabolism and neurodegenerative diseases. Different oxysterols are reported to be involved in numerous age-related pathological conditions. Among them, the balance of 24-hydroxycholesterol (24-OH) and 27-hydroxycholesterol (27-OH) has been identified as a useful tool for monitoring and/or diagnosing of the progression of neurodegenerative diseases (Poli, Biasi, and Leonarduzzi, 2013). By analyzing the patient samples, it was found that the increase in plasma $24-\mathrm{OH}$ level and $24-\mathrm{OH} / 27-\mathrm{OH}$ ratio is related with the development of eventual cognitive impairment (Hughes et al., 2012; Malaguti et al., 2019). Besides, 7-KC accumulation has been correlated to the development of AD. It exerts toxic effects on cellular model systems derived from neuronal tissues by multiple mechanisms (Malaguti et al., 2019). Although the direct effect of oral administration of oxysterols on neurodegenerative disease has rarely been reported, increasing evidence shows that oxysterols can impair neuronal and muscular development and induce oxidative stress, inflammation, amyloid $\beta$-protein $(\mathrm{A} \beta)$ formation and accumulation, and death of neurons in various human neuronal cell lines (Testa et al., 2018) (Figure 2).

\section{Gastrointestinal diseases}

A growing body of evidence suggests that long-term consumption of oxidized oils may be an important factor in human gastrointestinal diseases, and the cause is closely related to the large amount of generated LOPs (Martin Grootveld et al., 2020). Animal toxicology studies have shown that oxidized oils produced under extreme processing conditions induces severe irritation of gastrointestinal tract and could react with intestinal mucosal proteins and interfere with the absorption process in experimental animals (Esterbauer, 1993; Hajri, 2018). Obembe et al. (2011) found that ingestion of thermally oxidized palm oil may induce distortion in the morphology of intestinal villi, malabsorption of intestinal juice and glucose absorption in the intestine of rats. Zhou et al. (2016) reported that oral administration of fried oil induced impairment of intestinal mucosa, endocrine tissue destruction and inflammation, and microbiota structure imbalance in rats.

The formation of reactive $\alpha, \beta$-unsaturated aldehydes during high fat dietary intake are one of the major contributory factors in aggravation of gastric mucosa and intestinal diseases. They can directly contact intestine lamina, and induce the loss of intestinal epithelial barrier function and abnormal inflammatory response of the intestinal mucosa, and play crucial roles in the pathogenesis of inflammatory bowel disease (IBD) (Rossin et al., 2017; Sottero et al., 2018). Jayaraj et al. (1986) reported that oral administration of HNE to rats at a dose of only $0.26 \mu \mathrm{M}$, a concentration similar to that of healthy human blood plasma induced peptic ulcers in the animals. Gomes et al. (2002) found that acrolein $(6 \mathrm{mg} / \mathrm{kg})$ administration by gavage for 70 days in rats induced erosion, hyperplasia and hyperkeratosis in the glandular mucosa of the stomach or in the forestomach. Oral administration of tt-DDE $(800 \mathrm{mg} / \mathrm{kg})$ by gavage for 3 months can induce forestomach ulceration and diarrhea, and inhibit gastric emptying rate in rats through inducing cholecystokinin (CCK) secretion in rats (Chan, 2011; Hira et al., 2015). More recently, Rom et al. (2017) reported that intake of acrolein ( $3 \mathrm{mg} / \mathrm{kg} /$ day) for 1 month induced a major shift in the gut microbiota composition in atherosclerotic ApoE-/- mice, including a significant phylum-level change with increased Firmicutes and decreased Bacteroidetes.

For oxysterols, they are closely related to the occurrence and severity of intestinal inflammation and intestinal endothelial damage. Dietary intake of 7-ketocholesterol (7-KC) impaired the integrity of intestinal epithelial monolayer barrier by down-regulating tight junction protein zonule occlusion-1 (ZO-1) and reducing the transepithelial electrical resistance (Chalubinski et al., 2014; Chalubinski et al., 2013). According to the report presented by Willinger (2019), high amounts of oxysterols synthesized from dietderived cholesterols would activate the receptor $\mathrm{G}$ protein-coupled receptor 183 (GPR183) and trigger pro-inflammatory immune activity in the intestine. Besides, dietary oxysterols can induce irreversible damage of the intestinal epithelial, and can exert a series of toxic effects on human epithelial colonic cells, including mitochondrial injury, pro-apoptotic, pro-oxidation, pro-inflammatory activities, thereby impairing the characteristics of the intestinal epithelium (Sottero et al., 2018) (Figure 2).

\section{Carcinogenicity}

Evidence for a putative role of dietary oxidized oils and LOPs in carcinogenicity has come from both animal and human studies. Stott-Miller et al. (2013) examined the relationship between the intake of deep-fried foods (including French fries, fried chicken, fried fish, etc.) and prostate cancer risk through a food frequency questionnaire survey in 1,549 cases and 1,492 controls, and it was concluded that regular consumption of deep-fried foods is associated with increased prostate risk. Recently, Mhatre et al. (2020) conducted a human case-control study, showing that high consumption of fried mustard oil increased the risk of gallbladder cancer. On the other hand, the basis of the epidemiological studies suggested that cooking fumes from heated culinary oils are toxic and exposure to human showed to be an increased risk factor of contracting cancer (Chen et al., 2020; Jia et al., 2018). In particular, a positive correlation between the inhaling oil fume from heated oils and high risks of lung cancer (Ma et al., 2020).

Cumulative evidence indicated that lipid oxidation-derived reactive aldehydes may be the main carcinogenic substances in oxidized oils that exert carcinogenicity. It has been reported that aldehydes induce and participate in the occurrence and progression of cancer, and chronic exposure can increase the tumor frequency in animals (Eckl and Bresgen, 2017). For example, tt-DDE, a major aldehyde in cooking oils fumes, was reported to induce lung carcinogenesis. It has been reported that intratracheally instilled with tt-DDE to mice for 8 weeks significantly increased the number and types of cells in the bronchoalveolar lavage fluid, increased the epithelial hyperplasia and granulomatous nodules at the bronchoalveolar junction (Lin et al., 2014; Wang et al., 2010). Oral administering MDA as its enol salt over a range of $0.1-10.0 \mu \mathrm{g} / \mathrm{g} / \mathrm{day}$ for 12 months in Swiss mice showed a dose dependent increase of 


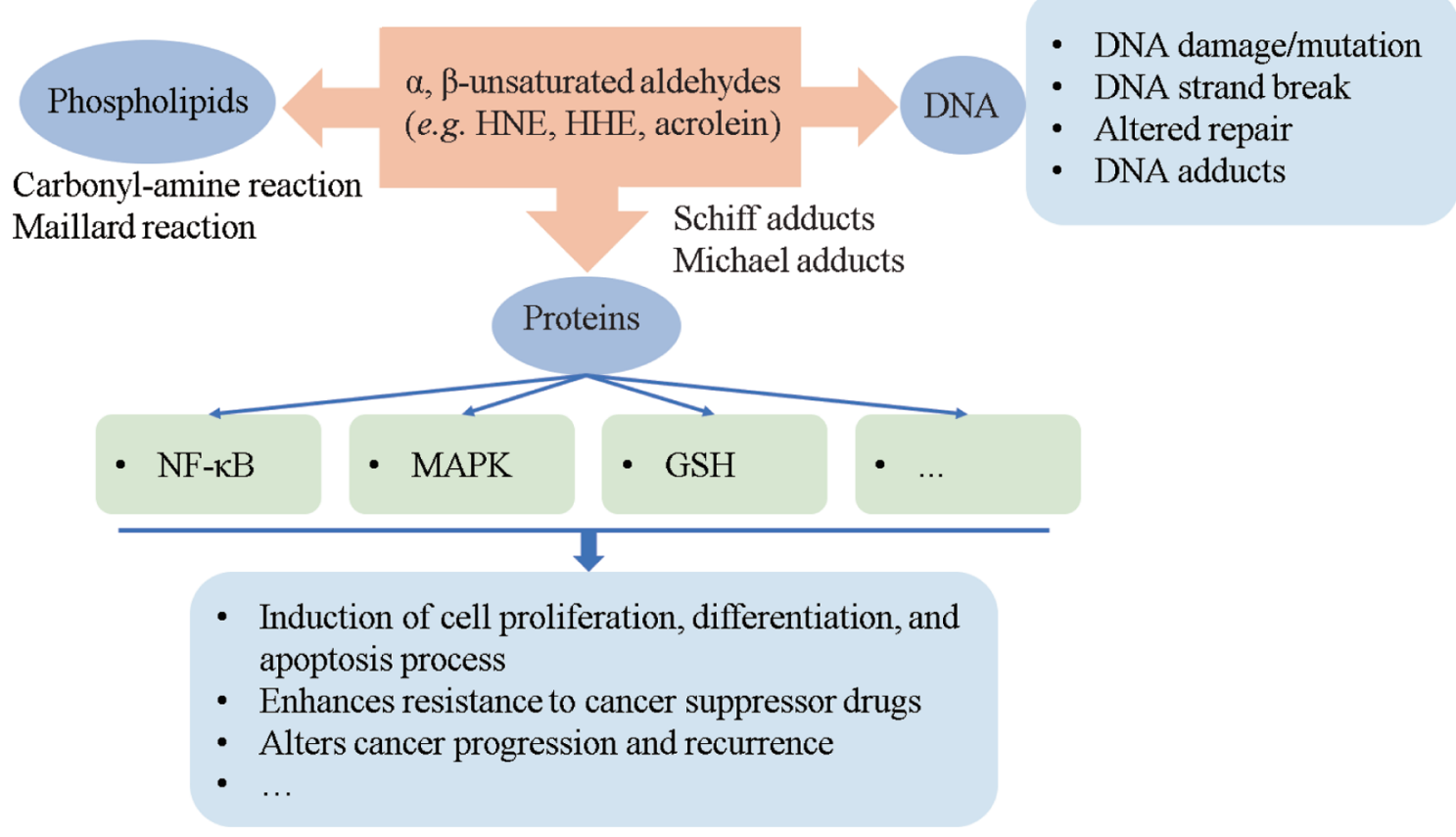

Figure 3. Summary of the formation of aldehyde adducts and their possible effects on the progression of cancer.

total neoplasms and neoplastic lesions in the liver (Draper, McGirr, and Hadley, 1986). Likewise, oral consumption of acrolein induced pulmonary injuries, including airspace enlargement, lung inflammation, lung edema, and even lung cancer (Bein and Leikauf, 2011).

The reported biochemical effects of aldehydes are associated with their lipophilicity and high reactivity (Figure 3). They can covalently interact with amino acids cysteine, histidine and lysine, DNA, phospholipids, protein, and sulfhydryl groups (Gęgotek and Skrzydlewska, 2019). Importantly, these aldehyde-induced DNA modification as well as protein adducts play key features in the growth and progression of cancer. Oral administration of HNE by gavage has been found to induce significant increases of 2'-deoxyguanosine (dGuo) adducts of HNE (HNE-dGp-adducts) and HNE protein adducts in different types of tumors, including liver, lung, renal, colon and forestomach of rats (Barrera, et al., 2015; Zarkovic, Jakovcevic, and Zarkovic, 2017). Hong et al. (2020) analyzed a total of 62 urothelial carcinomas patients, and found that acrolein-DNA (Acr-dG) levels were statistically correlated with chronic kidney disease stages in urothelial carcinomas patients. On the other hand, the formation of adducts affects protein function, triggering different mechanism, such as proliferation, cell differentiation and apoptosis, enhances resistance to cancer suppressor drugs, and alters cancer progression, among others (Cherkas and Zarkovic, 2018; Martín-Sierra et al., 2019).

The influence of dietary oxysterols on the incidence of cancer is still a controversial debate. As summarized by KloudovaSpalenkova et al. (2020), oxysterols not only play important roles in carcinogenesis, proliferation, migration, apoptosis and multiple signaling pathways, but also play many roles in cells in physiological and pathological conditions thus modulating cancer therapy. Besides, the involvements of oxysterols in hepatocellular carcinoma, pancreatic, colon cancer, and breast cancer have also been reviewed in recent years (Kovač et al.,2019; Nazih et al., 2020). They concluded that the role of oxysterols in carcinogenesis is far from being conclusive.

\section{Mutagenicity}

To date, some investigations have proven the mutagenic potential of orally administered oxidized oils and LOPs. Hageman et al. (1991) conducted a study to evaluate the mutagenicity of repeated heated oils containing oxidation products of linoleic acid in rats. Results showed that oral consumption the repeatedly heated oils at a level of $10 \%$ (by weight) for 4 weeks increased urine mutagenicity, and enhanced cell proliferation in the oesophagus of rats. Other studies performed on frying oil obtained by the conventional frying method showed that fatty acid oxidation products and their thermal degradation products produced by deep frying have mutagenic activity (Chen et al., 2003; Perez, Lopez de Cerain, and Bello, 2002). Generally, severe abusive thermal processing conditions, such as long heating times, high temperature, or overused heated oil, are necessary to produce appreciable mutagenic activity.

For aldehydic LOPs, Wu et al. (2001) reported that four enal compounds identified from the fumes of peanut oil at the dose of $10 \mu \mathrm{g}$ per plate were mutagenic to Salmonella Typhimurium TA98 and TA100, and the order of mutagenic activity was tt-DDE $>$ trans-trans-2,4-nonadienal (tt-2,4-NDE) $>$ trans-2-decenal (t2 -DCA) $>$ trans-2-undecenal (t-2-UDA). Likewise, Dung et al. (2006) reported that the major alkenal mutagenic compounds (tt-DDE, tt-2,4-NDE, t-2-DCA and t-2-UDA) from heated three cooking oils (soybean oil, sunflower oil, and lard) induced significant oxidative DNA damage by the 8-hydroxy-20-deoxyguanosine formation in A-549 cells at the concentrations from 50 to $200 \mu \mathrm{g} /$ $\mathrm{mL}$, which suggested that these aldehydes are generally both mutagenic and carcinogenic. Grúz et al. (2017) reported that both HNE and 2-hexenal induced base substitutions in the TA104 and TA100 Ames strains in a dose-dependent manner. Besides, in the review summarized by Eckl and Bresgen (2017), the mutagenicities of 2-hexenal, 2-heptenal, 2-octenal and 2-nonenal have been previously evaluated in bacterial systems, and each of these was found to exert significant effects at $\mu \mathrm{mol} / \mathrm{L}$ concentrations. The 
mutagenicity of MDA and acrolein tested in mammalian cell lines in the thioguanine resistance test and in the Ames test with different strains.

\section{Hepatotoxicity}

Substantial evidence shows that oxidized oils have hepatotoxic property, and animal studies have shown that they can induce varying degrees of liver damage regardless of short or long administration periods. These oxidized oils can disturb hepatic redox equilibrium and induce significant changes in the gene expressions related to fatty acid composition in animals (Ambreen, Siddiq, and Hussain, 2020; Ringseis and Eder, 2011). For example, Ringseis and Eder (2011) summarized the phenotypic changes and molecular mechanisms of lipid metabolism observed in oxidized oil feeding studies. They pointed out that oxidized oil played an important role in fatty acid synthesis, cholesterol homeostasis and lipoprotein metabolism. The gene expressions or activities of fatty acid synthase (FAS), peroxisome proliferator-activated receptor $\alpha(\operatorname{PPAR} \alpha)$, sterol regulatory element binding protein (SREBP), glucose-6-phosphate dehydrogenase (G6PDH), acyl coenzyme A (CoA) oxidase or cytochrome P450 (CYP)4A1 in the liver of rats were regulated. However, whether LOPs are the specific toxic compounds that exert hepatotoxicity remains unclear.

Aldehydes can be absorbed into the circulatory system, subsequent accumulate and harm various body tissues, particularly the liver (Grootveld et al., 1998). According to the results presented by Kanazawa et al. (1998), radio-labelled hexanal and HNE accumulated in the liver of rats with a slight hepatic hypertrophy after administration with radio-labelled hydroperoxides of linoleic acid. Kang and co-authors found that oral daily exposure to HNE $(0.5$ $\mathrm{mg} / \mathrm{kg}$ ) for 28 days produced hepatotoxicity in rats, as evidenced by significant alterations in serum albumin, serum total bilirubin, and aspartate aminotransferase (AST) activity (Kang et al., 2011). In addition to HNE, Gökçe et al. (2020) reported that consumption of acrolein $(4 \mathrm{mg} / \mathrm{kg})$ for 7 days by gavage induced liver tissues apoptosis in rats, as evidenced by chromatin condensation in the nucleus of hepatocytes, dilatations in the perinuclear space, and cytoplasmic vacuolization.

\section{Conclusions}

Consideration of the popularity of processed and fried foods and the wide-spread consumption of fast foods, the investigation of the effects of dietary LOPs on health is becoming increasingly important. The collected evidence suggests that the formation of LOPs not only reduces lipid nutritional properties but also represents a risk to human health. Nevertheless, due to the extremely complex processes in the human body, more systematic research about the effects of LOPs on human health are needed, such as the protection of antioxidant enzymes, the interaction of other components in diet, the role that intestinal flora plays in this process, and the effective method of inhibiting lipids oxidation.

\section{Acknowledgments}

This work was financially supported by "National Key R\&D Program of China (2018YFD0901000)", "The National Natural Science Foundation of China (31871759)", "Dalian Science and Technology Innovation Fund Project (2019J11CY005)" and "Cen- tral Funds Guiding the Local Science and Technology Development (No. 2020JH6/10500002)".

\section{References}

Ahotupa, M. (2017). Oxidized lipoprotein lipids and atherosclerosis. Free Radic. Res. 51(4): 439-447.

Ambreen, G., Siddiq, A., and Hussain, K. (2020). Association of long-term consumption of repeatedly heated mix vegetable oils in different doses and hepatic toxicity through fat accumulation. Lipids Health Dis. 19(1): 69.

Aydın, B., Atlı Şekeroğlu, Z., and Şekeroğlu, V. (2018). Effects of whey protein and conjugated linoleic acid on acrolein-induced cardiac oxidative stress, mitochondrial dysfunction and dyslipidemia in rats. Biomed. Pharmacother. 107: 901-907.

Barrera, G., Pizzimenti, S., Ciamporcero, E.S., Daga, M., Ullio, C., Arcaro, A. Cetrangolo, G.P., Ferretti, C., Dianzani, C., Lepore, A., and Gentile, F. (2015). Role of 4-hydroxynonenal-protein adducts in human diseases. Antioxid. Redox Signal. 22(18): 1681-1702.

Bein, K., and Leikauf, G.D. (2011). Acrolein - a pulmonary hazard. Mol. Nutr Food Res. 55(9): 1342-1360.

Chalubinski, M., Wojdan, K., Gorzelak, P., Borowiec, M., and Broncel, M. (2014). The effect of oxidized cholesterol on barrier functions and IL-10 mRNA expression in human intestinal epithelium co-cultured with dendritic cells in the transwell system. Food Chem. Toxicol. 69: 289-293.

Chalubinski, M., Zemanek, K., Skowron, W., Wojdan, K., Gorzelak, P., and Broncel, M. (2013). The effect of 7-ketocholesterol and 25-hydroxycholesterol on the integrity of the human aortic endothelial and intestinal epithelial barriers. Inflamm. Res. 62(12): 1015-1023.

Chan, P.C. (2011). NTP toxicity studies of toxicity studies of 2,4-decadienal (CAS No. 25152-84-5) administered by gavage to F344/N Rats and B6C3F1 mice. Toxic. Rep. Ser. (76): 1-94.

Chapple, S.J., Cheng, X., and Mann, G.E. (2013). Effects of 4-hydroxynonenal on vascular endothelial and smooth muscle cell redox signaling and function in health and disease. Redox Biol. 1: 319-331.

Charlton, K.M., Corner, A.H., Davey, K., Kramer, J.K., Mahadevan, S., and Sauer, F.D. (1975). Cardiac lesions in rats fed rapeseed oils. Can. J. Comp. Med. 39(3): 261-269.

Chen, T., Fang, Y., Chen, H., Chang, C., Huang, H., Chen, Y., Liao, K., Wu, H., Chang, G., Tsai, Y., Wang, C., Chen, Y., Huang, M., Su, W., Yang, P. Chen, C., Hsiao, C., and Hsiung, C. (2020). Impact of cooking oil fume exposure and fume extractor use on lung cancer risk in non-smoking Han Chinese women. Sci. Rep. 10(1): 6774

Chen, Y.Y., Liu, J.F., Chen, C.M., Chao, P.Y., and Chang, T.J. (2003). A study of the antioxidative and antimutagenic effects of Houttuynia cordata Thunb. using an oxidized frying oil-fed model. J. Nutr. Sci. Vitaminol. 49(5): 327-333.

Cherkas, A., and Zarkovic, N. (2018). 4-Hydroxynonenal in Redox Homeostasis of Gastrointestinal Mucosa: Implications for the Stomach in Health and Diseases. Antioxidants (Basel) 7(9): 118.

Cilla, A., Alegría, A., Attanzio, A., Garcia-Llatas, G., Tesoriere, L., and Livrea M.A. (2017). Dietary phytochemicals in the protection against oxysterol-induced damage. Chem. Phys. Lipids 207: 192-205.

Cohen, G., Riahi, Y., Sunda, V., Deplano, S., Chatgilialoglu, C., Ferreri, C. Kaiser, N., and Sasson, S. (2013). Signaling properties of 4-hydroxyalkenals formed by lipid peroxidation in diabetes. Free Radic. Biol. Med. 65: 978-987.

Cohn, J.S. (2002). Oxidized fat in the diet, postprandial lipaemia and cardiovascular disease. Curr. Opin. Lipidol. 13: 19-24.

Conklin, D.J., Barski, O.A., Lesgards, J.F., Juvan, P., Rezen, T., Rozman, D., Prough, R.A., Vladykovskaya, E., Liu, S., Srivastava, S., and Bhatnagar, A. (2010). Acrolein consumption induces systemic dyslipidemia and lipoprotein modification. Toxicol. Appl. Pharmacol. 243(1): 1-12.

Conklin, D.J., Bhatnagar, A., Cowley, H.R., Johnson, G.H., Wiechmann, R.J. Sayre, L.M., Trent, M.B., and Boor, P.J. (2006). Acrolein generation stimulates hypercontraction in isolated human blood vessels. Toxicol. Appl. Pharmacol. 217(3): 277-288.

Conklin, D.J., Prough, R.A., Juvan, P., Rezen, T., Rozman, D., Haberzettl, P. 
Srivastava, S., and Bhatnagar, A. (2011). Acrolein-induced dyslipidemia and acute-phase response are independent of HMG-CoA reductase. Mol. Nutr. Food Res. 55(9): 1411-1422.

Draper, H.H., McGirr, L.G., and Hadley, M. (1986). The metabolism of malondialdehyde. Lipids 21(4): 305-307.

Dung, C.H., Wu, S.C., and Yen, G.C. (2006). Genotoxicity and oxidative stress of the mutagenic compounds formed in fumes of heated soybean oil, sunflower oil and lard. Toxicol. In Vitro 20(4): 439-447.

Eckl, P.M., and Bresgen, N. (2017). Genotoxicity of lipid oxidation compounds. Free Radic. Biol. Med. 111: 244-252.

Endemann, D.H., and Schiffrin, E.L. (2004). Endothelial dysfunction. J. Am. Soc. Nephrol. 15(8): 1983-1992.

Endo, K., Oyama, T., Saiki, A., Ban, N., Ohira, M., Koide, N., Murano, T., Watanabe, H., Nishii, M., Miura, M., Sekine, K., Miyashita, Y., and Shirai, K. (2008). Determination of serum 7-ketocholesterol concentrations and their relationships with coronary multiple risks in diabetes mellitus. Diabetes Res. Clin. Pract. 80(1): 63-68.

Esterbauer, H. (1993). Cytotoxicity and genotoxicity of lipid-oxidation products. Am. J. Clin. Nutr. 57(5 Suppl): 779S-785S.

Ferderbar, S., Pereira, E.C., Apolinário, E., Bertolami, M.C., Faludi, A., Monte, O., Calliari, L.E., Sales, J.E., Gagliardi, A.R., Xavier, H.T., and Abdalla, D.S. (2007). Cholesterol oxides as biomarkers of oxidative stress in type 1 and type 2 diabetes mellitus. Diabetes Metab. Res. Rev. 23(1): 35-42.

Gargiulo, S., Testa, G., Gamba, P., Staurenghi, E., Poli, G., and Leonarduzzi, G. (2017). Oxysterols and 4-hydroxy-2-nonenal contribute to atherosclerotic plaque destabilization. Free Radic. Biol. Med. 111: 140-150.

Gęgotek, A., and Skrzydlewska, E. (2019). Biological effect of protein modifications by lipid peroxidation products. Chem. Phys. Lipids 221: 46-52.

Gianazza, E., Brioschi, M., Fernandez, A.M., and Banfi, C. (2019). Lipoxidation in cardiovascular diseases. Redox Biol. 23: 101119.

Gökçe, A.B., Eren, B., and Sağir, D. (2020). Inhibition of acrolein-induced apoptosis by the antioxidant selenium. Toxicol. Ind. Health 36(2): 84-92.

Gomes, R., Meek, M.E., and Eggleton, M. (2002). Concise International Chemical Assessment Document 43: Acrolein. Ipcs Concise International Chemical Assessment Documents.

Grootveld, M., Atherton, M.D., Sheerin, A.N., Hawkes, J., Blake, D.R., Richens, T.E., Silwood, C.J., Lynch, E., and Claxson, A.W. (1998). In vivo absorption, metabolism, and urinary excretion of alpha, beta-unsaturated aldehydes in experimental animals. Relevance to the development of cardiovascular diseases by the dietary ingestion of thermally stressed polyunsaturate-rich culinary oils. J. Clin. Invest. 101(6): 1210-1218.

Grootveld, M., Percival, B.C., Leenders, J., and Wilson, P.B. (2020). Potential Adverse Public Health Effects Afforded by the Ingestion of Dietary Lipid Oxidation Product Toxins: Significance of Fried Food Sources. Nutrients 12(4): 974.

Grúz, P., Shimizu, M., Sugiyama, K.I., and Honma, M. (2017). Mutagenicity of $\omega-3$ fatty acid peroxidation products in the Ames test. Mutat. Res. 819: 14-19.

Guillén, M.D., and Goicoechea, E. (2008). Toxic Oxygenated $\alpha, \beta$-Unsaturated Aldehydes and their Study in Foods: A Review. Crit. Rev. Food Sci. Nutr. 48(2): 119-136.

Hageman, G., Verhagen, H., Schutte, B., and Kleinjans, J. (1991). Biological effects of short-term feeding to rats of repeatedly used deep-frying fats in relation to fat mutagen content. Food Chem. Toxicol. 29(10): 689-698.

Hajri, T. (2018). Effects of oxidized lipids and lipoproteins on cardiac function. Front. Biosci. (Landmark Ed) 23: 1822-1847.

Hira, T., Yahagi, A., Nishimura, S., Sakaino, M., Yamashita, T., and Hara, H. (2015). Diunsaturated Aldehyde, trans,trans-2,4-Decadienal in the Intestinal Lumen Suppresses Gastric Emptying through Serotonin Signaling in Rats. J. Agric. Food Chem. 63(37): 8177-8181.

Hong, J.H., Lee, P.A.H., Lu, Y.C., Huang, C.Y., Chen, C.H., Chiang, C.H., Chow, P.M., Jaw, F.S., Wang, C.C., Huang, C.Y., Wang, T.W., Liu, J.H., and Wang H.T. (2020). Acrolein contributes to urothelial carcinomas in patients with chronic kidney disease. Urol. Oncol. 38(5): 465-475.

Hu, Y., Yin, F., Yu, Z., Peng, Y., Zhao, G., Liu, Z., Zhou, D., Ma, X., Shahidi, F., and Zhu, B. (2020). Trans, trans-2,4-decadienal impairs vascular endothelial function by inducing oxidative/nitrative stress and apoptosis. Redox Biol. 34: 101577.

Huang, Y.J., Zhang, L., Shi, L.Y., Wang, Y.Y., Yang, Y.B., Ke, B., Zhang, T.Y., and
Qin, J. (2018). Caloric restriction ameliorates acrolein-induced neurotoxicity in rats. Neurotoxicology 65: 44-51.

Hughes, T.M., Kuller, L.H., Lopez, O.L., Becker, J.T., Evans, R.W., Sutton-Tyrrell, K., and Rosano, C. (2012). Markers of cholesterol metabolism in the brain show stronger associations with cerebrovascular disease than Alzheimer's disease. J. Alzheimers Dis. 30(1): 53-61.

Jaganjac, M., Tirosh, O., Cohen, G., Sasson, S., and Zarkovic, N. (2013). Reactive aldehydes--second messengers of free radicals in diabetes mellitus. Free Radic. Res. 47: 39-48.

Jayaraj, A.P., Rees, K.R., Tovey, F.I., and White, J.S. (1986). A molecular basis of peptic ulceration due to diet. Br. J. Exp. Pathol. 67(1): 149-155

Jia, P.L., Zhang, C., Yu, J.J., Xu, C., Tang, L., and Sun, X. (2018). The risk of lung cancer among cooking adults: a meta-analysis of 23 observational studies. J. Cancer Res. Clin. Oncol. 144(2): 229-240.

Kamisah, Y., Ang, S., Othman, F., Nurul-Iman, B., and Qodriyah, H. (2016). Renoprotective effect of virgin coconut oil in heated palm oil dietinduced hypertensive rats. Appl. Physiol. Nutr. Metab. 41(10): 10331038

Kanazawa, K., and Ashida, H. (1998). Dietary hydroperoxides of linoleic acid decompose to aldehydes in stomach before being absorbed into the body. Biochim. Biophys. Acta. 1393: 349-361.

Kang, S.C., Kim, H.W., Kim, K.B., Kwack, S.J., Ahn, I.Y., Bae, J.Y., Lim, S.K., and Lee, B.M. (2011). Hepatotoxicity and nephrotoxicity produced by 4-hydroxy-2-nonenal (4-HNE) following 4-week oral administration to Sprague-Dawley rats. J. Toxicol. Environ. Health A. 74(12): 779-789.

Kanner, J. (2007). Dietary advanced lipid oxidation endproducts are risk factors to human health. Mol. Nutr. Food Res. 51(9): 1094-1101.

Kloudova-Spalenkova, A., Holy, P., and Soucek, P. (2020). Oxysterols in cancer management: From therapy to biomarkers. Br. J. Pharmacol. 178(16): 3235-3247.

Kovač, U., Skubic, C., Bohinc, L., Rozman, D., and Režen, T. (2019). Oxysterols and Gastrointestinal Cancers Around the Clock. Front. Endocrinol. 10: 483.

Lee, D.H., Nam, Y.J., and Lee, C.S. (2015). Apocynin attenuates cholesterol oxidation product-induced programmed cell death by suppressing NF-KB-mediated cell death process in differentiated PC12 cells. Neurochem. Int. 89: 28-39.

Lee, S.E., and Park, Y.S. (2013). Role of lipid peroxidation-derived $\alpha$, $\beta$-unsaturated aldehydes in vascular dysfunction. Oxid. Med. Cell Longev. 2013: 629028.

Leonarduzzi, G., Chiarpotto, E., Biasi, F., and Poli, G. (2010). 4-Hydroxynonenal and cholesterol oxidation products in atherosclerosis. Mol. Nutr. Food Res. 49(11): 1044-1049.

Leong, X.F., Aishah, A., Nor Aini, U., Das, S., and Jaarin, K. (2008). Heated palm oil causes rise in blood pressure and cardiac changes in heart muscle in experimental rats. Arch. Med. Res. 39(6): 567-572.

Leong, X.F., Najib, M.N., Das, S., Mustafa, M.R., and Jaarin, K. (2009). Intake of repeatedly heated palm oil causes elevation in blood pressure with impaired vasorelaxation in rats. Tohoku J. Exp. Med. 219(1): 71-78.

Li, X., Yu, X., Sun, D., Li, J., Wang, Y., Cao, P., and Liu, Y. (2017). Effects of Polar Compounds Generated from the Deep-Frying Process of Palm Oil on Lipid Metabolism and Glucose Tolerance in Kunming Mice. J. Agric. Food Chem. 65(1): 208-215.

Liao, C.H., Shaw, H.M., and Chao, P.M. (2008). Impairment of glucose metabolism in mice induced by dietary oxidized frying oil is different from that induced by conjugated linoleic acid. Nutrition 24: 744-752.

Lin, P., Lee, H.L., Cheng, H.I., Chen, C.Y., Tsai, M.H., and Liu, H.J. (2014). Metabolomic profiling of mice urine and serum associated with transtrans 2, 4-decadienal induced lung lesions by liquid chromatographymass spectrometry. Anal. Bioanal. Chem. 406(17): 4287-4297.

Ma, Y., Deng, L., Ma, P., Wu, Y., Yang, X., Xiao, F., and Deng, Q. (2020). In vivo respiratory toxicology of cooking oil fumes: Evidence, mechanisms and prevention. J. Hazard. Mater. 402: 123455.

Malaguti, M., Cardenia, V., Rodriguez-Estrada, M.T., and Hrelia, S. (2019). Nutraceuticals and physical activity: Their role on oxysterols-mediated neurodegeneration. J. Steroid. Biochem. Mol. Biol. 193: 105430.

Maldonado-Pereira, L., Schweiss, M., Barnaba, C., and Medina-Meza, I.G. (2018). The role of cholesterol oxidation products in food toxicity. Food Chem. Toxicol. 118: 908-939.

Mali, V.R., Pan, G., Deshpande, M., Thandavarayan, R.A., Xu, J., Yang, X.P., and Palaniyandi, S.S. (2016). Cardiac Mitochondrial Respiratory Dys- 
function and Tissue Damage in Chronic Hyperglycemia Correlate with Reduced Aldehyde Dehydrogenase-2 Activity. PLoS One 11(10): e0163158.

Martín-Sierra, C., Laranjeira, P., Domingues, M.R., and Paiva, A. (2019). Lipoxidation and cancer immunity. Redox Biol. 23: 101103.

Menéndez-Carreño, M., Varo, N., Mugueta, C., Restituto, P., Ansorena, D., and Astiasarán, I. (2011). Correlation between serum content of the main COPs (cholesterol oxidation products) from autoxidation and cardiovascular risk factors. Nutr. Hosp. 26(1): 144-151.

Meynier, A., Lherminier, J., Demaison-Meloche, J., Ginies, C., Grandgirard, A., and Demaison, L. (2002). Effects of dietary oxysterols on coronary arteries in hyperlipidaemic hamsters. Br. J. Nutr. 87(5): 447-458.

Mhatre, S., Rajaraman, P., Chatterjee, N., and Bray, F. (2020). Mustard oil consumption, cooking method, diet and gallbladder cancer risk in high- and low-risk regions of India. Int. J. Cancer 147(6): 1621-1628.

Nakamura, K., Kusano, K.F., Matsubara, H., Nakamura, Y., Miura, A., Nishii, N., Banba, K., Nagase, S., Miyaji, K., Morita, H., Saito, H., Emori, T., and Ohe, T. (2005). Relationship between oxidative stress and systolic dysfunction in patients with hypertrophic cardiomyopathy. J. Card. Fail. 11(2): 117-123.

Nazih, H., and Bard, J. (2020). Cholesterol, Oxysterols and LXRs in Breast Cancer Pathophysiology. Int. J. Mol. Sci. 21: 1356.

Nkanu, E.E., Owu, D.U., and Osim, E.E. (2018). Altered Potassium Ion Channel Function as a Possible Mechanism of Increased Blood Pressure in Rats Fed Thermally Oxidized Palm Oil Diets. J. Diet. Suppl. 15(4): 431-444.

Nurul-Iman, B., Kamisah, Y., Jaarin, K., and Qodriyah, H. (2013). Virgin coconut oil prevents blood pressure elevation and improves endothelia functions in rats fed with repeatedly heated palm oil. Evidence-based complementary and alternative medicine. Evid. Based Complement. Alternat. Med. 2013: 629329

Obembe, A.O., Owu, D.U., Okwari, O.O., Antai, A.B., and Osim, E.E. (2011). Intestinal Fluid and Glucose Transport in Wistar Rats following Chronic Consumption of Fresh or Oxidised Palm Oil Diet. ISRN Gastroenterol. 2011: 972838

Perez, C., Lopez de Cerain, A., and Bello, J. (2002). Modulation of mutagenic activity in meat samples after deep-frying in vegetable oils. Mutagenesis 17(1): 63-66

Perluigi, M., Coccia, R., and Butterfield, D.A. (2012). 4-Hydroxy-2-nonenal, a reactive product of lipid peroxidation, and neurodegenerative diseases: a toxic combination illuminated by redox proteomics studies. Antioxid. Redox Signal. 17(11): 1590-1609.

Pillon, N.J., Croze, M.L., Vella, R.E., Soulère, L., Lagarde, M., and Soulage, C.O. (2012). The lipid peroxidation by-product 4-hydroxy-2-nonenal (4-HNE) induces insulin resistance in skeletal muscle through both carbonyl and oxidative stress. Endocrinology 153(5): 2099-2111.

Pillon, N.J., Vella, R.E., Souleere, L., Becchi, M., Lagarde, M., and Soulage, C.O. (2011). Structural and functional changes in human insulin induced by the lipid peroxidation byproducts 4-hydroxy-2-nonenal and 4-hydroxy-2-hexenal. Chem. Res. Toxicol. 24(5): 752-62.

Poli, G., Biasi, F., and Leonarduzzi, G. (2013). Oxysterols in the pathogenesis of major chronic diseases. Redox Biol. 1(1): 125-130.

Ringseis, R., and Eder, K. (2011). Regulation of genes involved in lipid metabolism by dietary oxidized fat. Mol. Nutr. Food Res. 55(1): 109-121.

Rodriguez-Amaya, D.B., and Shahidi, F. (2021). Oxidation of lipids. Chemical Changes during Processing and Storage of Foods. Academic Press, pp. 125-170.

Rom, O., Korach-Rechtman, H., Hayek, T., Danin-Poleg, Y., Bar, H., Kashi, Y., and Aviram, M. (2017). Acrolein increases macrophage atherogenicity in association with gut microbiota remodeling in atherosclerotic mice: protective role for the polyphenol-rich pomegranate juice. Arch. Toxicol. 91(4): 1709-1725.

Rossin, D., Calfapietra, S., Sottero, B., Poli, G., and Biasi, F. (2017). HNE And Cholesterol Oxidation Products In Colorectal Inflammation And Carcinogenesis. Free Radic. Biol. Med. 111: 186-195.

Rouaki, F., Mazari, A., Kanane, A., Errahmani, M.B., and Ammouche, A. (2013). Cardiotoxicity induced by dietary oxidized sunflower oil in rats: pro- and antioxidant effects of $\alpha$-tocopherol. Int. J. Vitam. Nutr. Res. 83(6): 367-376.

Samadi, A., Gurlek, A., Sendur, S.N., Karahan, S., Akbiyik, F., and Lay, I. (2019). Oxysterol species: reliable markers of oxidative stress in dia- betes mellitus. J. Endocrinol. Invest. 42(1): 7-17.

Sardar Sinha, M., Villamil Giraldo, A.M., Öllinger, K., Hallbeck, M., and Civitelli, L. (2018). Lipid vesicles affect the aggregation of 4-hydroxy2-nonenal-modified $\alpha$-synuclein oligomers. Biochim. Biophys. Acta Mol. Basis Dis. 1864(9 Pt B): 3060-3068.

Selmanoğlu, G., Mülayimçelik Özgün, G., and Karacaoğlu, E. (2018). Acrolein-mediated neurotoxicity in growing Wistar male rats. Pestic. Biochem. Physiol. 149: 37-43.

Shahidi, F., and Zhong, Y. (2010). Lipid oxidation and improving the oxidative stability. Chem. Soc. Rev. 39(11): 4067-79.

Siti, H., Kamisah, Y., Nur lliyani, M., Mohamed, S., and Jaarin, K. (2017). Citrus leaf extract reduces blood pressure and vascular damage in repeatedly heated palm oil diet-Induced hypertensive rats. Biomed. Pharmacother. 87: 451-460.

Siti, H.N., Kamisah, Y., Mohamed, S., and Jaarin, K. (2018). Effects of citrus leaf extract on aortic vascular reactivity in hypertensive rats fed repeatedly heated vegetable oil. Appl. Physiol. Nutr. Metab. 44(4): 373-380.

Soriguer, F., Rojo-Martínez, G., Dobarganes, M.C., García Almeida, J.M., Esteva, I., Beltrán, M., Ruiz De Adana, M.S., Tinahones, F., Gómez-Zumaquero, J.M., García-Fuentes, E., and González-Romero, S. (2003). Hypertension is related to the degradation of dietary frying oils. Am. J. Clin. Nutr. 78(6): 1092-1097.

Sottero, B., Rossin, D., Poli, G., and Biasi, F. (2018). Lipid Oxidation Products in the Pathogenesis of Inflammation-related Gut Diseases. Curr. Med. Chem. 25(11): 1311-1326.

Soulage, C.O., Sardón Puig, L., Soulère, L., Zarrouki, B., Guichardant, M., Lagarde, M., and Pillon, N.J. (2018). Skeletal muscle insulin resistance is induced by 4-hydroxy-2-hexenal, a by-product of $n-3$ fatty acid peroxidation. Diabetologia 61(3): 688-699.

Sozen, E., Yazgan, B., and Sahin, A. (2018). High Cholesterol Diet-Induced Changes in Oxysterol and Scavenger Receptor Levels in Heart Tissue. Oxid. Med. Cell Longev. 2018: 8520746.

Srivastava, S., Sithu, S.D., Vladykovskaya, E., Haberzettl, P., Hoetker, D.J., Siddiqui, M.A., Conklin, D.J., D'Souza, S.E., and Bhatnagar, A. (2011) Oral exposure to acrolein exacerbates atherosclerosis in apoE-null mice. Atherosclerosis 215(2): 301-308.

Staprans, I., Hardman, D.A., Pan, X.M., and Feingold, K.R. (1999). Effect of oxidized lipids in the diet on oxidized lipid levels in postprandial serum chylomicrons of diabetic patients. Diabetes Care 22(2): 300-306.

Staprans, I., Pan, X.M., Rapp, J.H., and Feingold, K.R. (2005). The role of dietary oxidized cholesterol and oxidized fatty acids in the development of atherosclerosis. Mol. Nutr. Food Res. 49(11): 1075-1082.

Staprans, I., Pan, X.M., Rapp, J.H., Grunfeld, C., and Feingold, K.R. (2000) Oxidized cholesterol in the diet accelerates the development of atherosclerosis in LDL receptor- and apolipoprotein E-deficient mice. Arterioscler. Thromb. Vasc. Biol. 20(3): 708-714.

Stott-Miller, M., Neuhouser, M.L., and Stanford, J.L. (2013). Consumption of deep-fried foods and risk of prostate cancer. Prostate 73(9): 960-969.

Testa, G., Rossin, D., Poli, G., Biasi, F., and Leonarduzzi, G. (2018). Implication of oxysterols in chronic inflammatory human diseases. Biochimie 153: 220-231.

Vieira, S.A., Zhang, G., and Decker, E.A. (2017). Biological Implications of Lipid Oxidation Products. J. Am. Oil Chem. Soc. 94(3): 339-351.

Viktorinova, A., Svitekova, K., Stecova, A., and Krizko, M. (2016). Relationship between selected oxidative stress markers and lipid risk factors for cardiovascular disease in middle-aged adults and its possible clinical relevance. Clin. Biochem. 49(12): 868-872.

Wang, C.K., Chang, L.W., Chang, H., Yang, C.H., Tsai, M.H., Tsai, H.T., and Lin, P. (2010). Pulmonary changes induced by trans,trans-2,4-decadienal, a component of cooking oil fumes. Eur. Respir. J. 35(3): 667-675.

Wang, G.W., Guo, Y., Vondriska, T.M., Zhang, J., Zhang, S., Tsai, L.L., Zong, N.C., Bolli, R., Bhatnagar, A., and Prabhu, S.D. (2008). Acrolein consumption exacerbates myocardial ischemic injury and blocks nitric oxide-induced PKC $\varepsilon$ signaling and cardioprotection. J. Mol. Cell. Cardiol. 44(6): 1016-1022.

Willinger, T. (2019). Oxysterols in intestinal immunity and inflammation. J. Intern. Med. 285(4): 367-380.

Wu, S.C., Yen, G.C., and Sheu, F. (2001). Mutagenicity and identification of mutagenic compounds of fumes obtained from heating peanut oil. J. Food Prot. 64(2): 240-245. 
Yoshioka, N., Adachi, J., Ueno, Y., and Yoshida, K. (2005). Oxysterols increase in diabetic rats. Free Radic. Res. 39(3): 299-304.

Zaguri, R., Verbovetski, I., Atallah, M., Trahtemberg, U., Krispin, A., Nahari, E., Leitersdorf, E., and Mevorach, D. (2007). 'Danger' effect of lowdensity lipoprotein (LDL) and oxidized LDL on human immature dendritic cells. Clin. Exp. Immunol. 149(3): 543-552.

Zárate, J., Goicoechea, E., Pascual, J., Echevarría, E., and Guillén, M.D. (2009). A study of the toxic effect of oxidized sunflower oil containing 4-hydroperoxy-2-nonenal and 4-hydroxy-2-nonenal on cortical TrkA receptor expression in rats. Nutr. Neurosci. 12(6): 249-259.
Zarkovic, K., Jakovcevic, A., and Zarkovic, N. (2017). Contribution of the HNE-immunohistochemistry to modern pathological concepts of major human diseases. Free Radic. Biol. Med. 111: 110-126.

Zhou, Z., Wang, Y., Jiang, Y., Diao, Y., Strappe, P., Prenzler, P., Ayton, J., and Blanchard, C. (2016). Deep-fried oil consumption in rats impairs glycerolipid metabolism, gut histology and microbiota structure. Lipids Health Dis. 15(1): 86.

Zirak, M.R., Mehri, S., Karimani, A., Zeinali, M., Hayes, A.W., and Karimi, G. (2019). Mechanisms behind the atherothrombotic effects of acrolein, a review. Food Chem. Toxicol. 129: 38-53. 